\title{
Guidelines of the Brazilian Dermatology Society for diagnosis, treatment and follow up of primary cutaneous melanoma - Part I*
}

\author{
Luiz Guilherme Martins Castro ${ }^{1,2,3}$ \\ Walter Loureiro ${ }^{5}$ \\ João Pedreira Duprat Neto ${ }^{7}$ \\ Flávia Vasques Bittencourt ${ }^{8}$ \\ Sérgio Schrader Serpa ${ }^{10}$ \\ Gabriel Gontijo ${ }^{8}$
}

\author{
Maria Cristina Messina ${ }^{1,2,3,4}$ \\ Ricardo Silvestre Macarenco ${ }^{1,6}$ \\ Thais Helena Bello Di Giacomo $0^{1,2,3}$ \\ Renato Marchiori Bakos ${ }^{9}$ \\ Hamilton Ometto Stolf ${ }^{11}$
}

DOI: http:/ /dx.doi.org/10.1590/abd1806-4841.20154707

\begin{abstract}
The last Brazilian guidelines on melanoma were published in 2002. Development in diagnosis and treatment made updating necessary. The coordinators elaborated ten clinical questions, based on PICO system. A Medline search, according to specific MeSH terms for each of the 10 questions was performed and articles selected were classified from A to D according to level of scientific evidence. Based on the results, recommendations were defined and classified according to scientific strength. The present Guidelines were divided in two parts for editorial and publication reasons. In the first part, the following clinical questions were answered: 1) The use of dermoscopy for diagnosis of primary cutaneous melanoma brings benefits for patients when compared with clinical examination? 2) Does dermoscopy favor diagnosis of nail apparatus melanoma? 3) Is there a prognostic difference when incisional or excisional biopsies are used? 4) Does revision by a pathologist trained in melanoma contribute to diagnosis and treatment of primary cutaneous melanoma? What margins should be used to treat lentigo maligna melanoma and melanoma in situ?

Keywords: Dermoscopy; Diagnostic imaging; Diagnostic techniques and procedures; Guideline; Histology; Melanoma; Practice guideline; Sentinel lymph node biopsy; Therapeutics
\end{abstract}

\section{INTRODUCTION}

Cutaneous melanoma $(\mathrm{CM})$ is one of the most potentially dangerous forms of skin cancers, accounting for approximately $90 \%$ of deaths. The dermatologist is in the forefront of diagnosis and treatment of CM. It is his duty to keep updated on best practices in diagnosis, treatment and disease monitoring to be able to diagnose, treat and council patients in the best way.
The last Brazilian guidelines on $\mathrm{CM}$ were published in 2002. ${ }^{1}$ Over 10 years have passed and important advances in the area occurred during this period, with greater relevance to diagnostic techniques. Although some concepts have not changed, it is necessary to update the standards of practice on this important health problem.

\footnotetext{
Received on 07.05 .2015

Approved by the Advisory Board and accepted for publication on 13.07.2015

Study performed at Departamento de Oncologia - Sociedade Brasileira de Dermatologia (SBD) - Rio de Janeiro (RJ), Brazil. Financial Support: None.

Conflict of Interest: None.

Hospital Israelita Albert Einstein - São Paulo (SP) Brazil.

Hospital Alemão Oswaldo Cruz - São Paulo (SP) Brazil

Oncoderma - São Paulo (SP) Brazil.

Hospital Ipiranga - São Paulo (SP) Brazil.

Universidade Estadual do Pará (UEPA) - Belém (SP) Brazil.

Instituto do Câncer do Estado de São Paulo (ICESP) - São Paulo (SP) Brazil.

Departamento de Câncer de Pele A. C. Camargo Cancer Center- São Paulo (SP) Brazil.

Universidade Federal de Minas Gerais (UFMG) - Belo Horizonte (MG) Brazil.

Universidade Federal do Rio Grande do Sul (UFRGS) - Hospital de Clínicas de Porto Alegre, Porto Alegre (RS), Brazil.

Universidade Estácio de Sá (UNESA) - Rio de Janeiro (RJ) Brazil.

Universidade Estadual Paulista "Júlio de Mesquita Filho" (UNESP) - Botucatu (SP), Brazil.

(C2015 by Anais Brasileiros de Dermatologia
} 
These guidelines are intended for diagnostic and therapeutic approach and follow-up of patients with suspected or confirmed diagnoses of primary $\mathrm{CM}$ (PCM) with no clinical nor histological evidence of metastatic disease (stages 0, I and II). They do not include ocular nor mucosal melanoma.

\section{OBJECTIVE}

To introduce the most advanced evidences in diagnosis, therapeutic management and monitoring of PCM clinical stages 0, I and II patients, describing diagnostic peculiarities that allow identification of these tumors in early stages, as well as measures most widely accepted for treatment and follow-up in the context of Brazilian dermatology.

\section{METHOD - DESCRIPTION OF EVIDENCE COLLECTION}

The coordinators have defined 10 questions that reflect issues of clinical relevance on the subject. The questions were structured according to the acronym PICO (patient or population, intervention, comparison or control and outcome), according to regulations of the National Health Agency, the Brazilian Medical Association and Federal Council of Medicine, described in "The process of development, validation and implementation of clinical guidelines in the private healthcare system in Brazil". ${ }^{2}$ To answer these questions, a literature review of scientific articles was conducted in MEDLINE database. Search for evidence was limited primarily to articles published between 01/01/2009 and 06/30/2014 and keywords (MeSH terms) present in the title and/or summary were used, grouped into specific syntaxes for each of the 10 questions alone, as described in Chart 1.

After reading the abstracts, articles containing information relevant to the subject were selected. When appropriate, references present in these papers were selected, without limit for publication period, and were analyzed using the same methodology as that for the primarily selected studies.
Articles that presented the expected contribution were analyzed regarding the level of evidence (Table 2). Recommendations were written in response to the questions elaborated. Recommendations were also graduated according to level of evidence (Chart 2).

\section{RESULTS AND DISCUSSION}

Discussion and recommendations for the first 5 questions appear below. The other 5 questions will be presented in a new publication.

1) Is the use of dermoscopy for diagnosis of PCM beneficial for patients with suspicious lesions when compared to clinical examination?

For many years dermatologists could only rely on clinical diagnosis when facing a suspicious melanoma lesion. Implications of such diagnosis justified extreme measures such as removal of large amounts of suspicious lesions, which subsequently revealed to be benign (unnecessary resections).

A major step in improving accuracy of diagnosis of primary cutaneous melanoma (PCM) occurred with the introduction of "Melanoma ABCD" rule, acronym introduced in 1985, using the initials of four clinical features of skin lesions that may be indicative of malignancy (Asymmetry, irregular Borders, varied Colors and Diameter $>6 \mathrm{~mm}) .{ }^{3}$ Although increasing

Chart 2: Grade of recommendation and level of evidence:

\footnotetext{
A: Experimental or observational studies of higher consistency.

B: Experimental or observational studies of lower consistency.

C: Case reports / uncontrolled studies.

D: Opinion without critical evaluation, based on consensus, physiological studies or animal models.
}

Снart 1: Terms of the descriptors used to research each question and number of selected articles

\begin{tabular}{|lll|}
\hline Question & Terms & Number of articles \\
1 & (dermoscopy OR dermatoscopy) AND melanoma AND diagnosis & 339 \\
2 & (dermoscopy OR dermatoscopy) AND melanoma AND (nail OR subungual) & 21 \\
3 & (excisional OR incisional) AND melanoma AND biopsy AND prognosis & 13 \\
4 & pathology review AND melanoma & 9 \\
5 & (therapy OR treatment) AND (lentigo maligna OR melanoma in situ) & 903 \\
\hline
\end{tabular}


diagnosis sensitivity and specificity, the number of nevus excised for diagnosing a melanoma was still high. A few years later the letter " $E$ " was included in the acronym to represent "Evolution" or changes in the appearance of a suspicious lesion. ${ }^{4,5}$

Dermoscopy (DMCP) enables the examination of skin lesions, melanocytic or not, and the observation of structures and colors of the epidermis, dermo-epidermal junction and superficial dermis, not visible to the naked eye. These findings correlate with histological features and are used to determine whether the lesion is malignant or benign and if surgical removal is indicated. When integrated with information obtained from the clinical history and macroscopic examination, DMCP allows obtaining such a large amount of information, that it has gradually became an irreplaceable instrument for the dermatologist, such as the stethoscope is for the clinician.

Naked eye diagnostic sensitivity for PCM (percentage of correctly diagnosed melanomas) is around $71 \%$ whereas with the use of dermatoscope is $90 \%$. A meta-analysis of 22 studies showed that diagnostic accuracy was higher than naked eye examination when experts used DMCP (sensitivity $89 \%$ and specificity $79 \%$ ) (level of evidence A). ${ }^{6}$ There was no decrease in specificity, suggesting that the DMCP increases diagnostic accuracy without increasing the number of undiagnosed melanomas (level of evidence A) ${ }^{7,8}$

To achieve these higher efficiency levels it is necessary to use an algorithm for analyzing suspicious skin lesions. The 4 best known are: Menzies' scoring method; pattern analysis; 7-points check list; and $\mathrm{ABCD}$ of $\mathrm{DMCP}$, which - it's important to note - is different from the clinical ABCD. ${ }^{9}$ At a consensus DMCP experts meeting, standard analysis algorithm reached the highest specificity, sensitivity and accuracy for melanoma detection when compared with the other 3 algorithms (level of evidence B). ${ }^{10}$ Any of these algorithms presents higher effectiveness than examination with naked eye (level of evidence A). ${ }^{711-13}$ In summary, when using DMCP to evaluate any suspicious lesion, compared with evaluation by the naked eye, the probability of classifying an actual malignant lesion as malignant is higher, as well as classifying as benign a truly benign lesion. At this point it is important to remember that even with the use of DMCP accuracy of diagnosis melanoma does not reach $100 \%$. This is due to the lack of dermoscopic features suggestive of the diagnosis in very early lesions or in some cases of uncharacteristic melanomas (featureless). ${ }^{6,14}$

In addition to increased PCM diagnostic accuracy, use of DMCP presents 2 more clear benefits: reduction of unnecessary resections and increased diagnosis of non-melanoma skin cancer (level of evidence A) ${ }^{15-18} \mathrm{~A}$ randomized study showed $42 \%$ decrease in the number of unnecessary biopsies. ${ }^{16}$ This finding is similar to a retrospective study of excisions of pigmented lesions performed before and after training in DMCP. The rate of benign/ malignant lesions decreased from 18.0: 1 to 4.3: 1 (level of evidence A). ${ }^{16}$

Importantly, the effectiveness DMCP use depends on formal training and experience. It was demonstrated that dermatologists with formal training and at least 3-years experience in DMCP reach higher $\mathrm{CM}$ detection rates than non-trained dermatologists (level of evidence B). ${ }^{19}$ This learning process is time consuming and in the early stages of the learning curve worsening of accuracy can occur. ${ }^{20}$ Dermatologists, physicians from other specialties, paramedical staff and even medical students have consistently improved diagnosis accuracy after being trained in DMCP use (level of evidence A). A considerable number of dermatologists believe that the time required for training in DMCP is excessive. ${ }^{21}$ At the same time, some studies show a low level of satisfaction among chief-residents of dermatology in relation to training in DMCP. Many want more intense instruction in the area. There are also complaints about the limited availability of courses (level of evidence C). ${ }^{22}$

\section{Recommendations:}

- DMCP increases diagnostic accuracy of PCM compared to clinical examination. It should be used routinely in the evaluation of melanocytic lesions (grade of recommendation A);

- The use of DMCP for this purpose requires specific training in order to achieve the desired accuracy (grade of recommendation $\mathrm{A}$ ).

- In addition to being useful in diagnosing PCM, regular use of DMCP also has the advantage of reducing the number of unnecessary excisions (grade of recommendation $\mathrm{A}$ );

- In addition to being useful in diagnosing PCM and reducing the number of unnecessary excisions, regular use of DMCP leads to an increase in diagnosis of non-melanoma skin cancer (grade of recommendation A).

2) Does dermoscopy favor diagnosis of primary cutaneous melanoma of the nail apparatus (NA)?

NA-PCM represents $0.7 \%$ to $3.5 \%$ of all melanomas. ${ }^{23,24}$ Although deemed little frequent when considering that the palm is equivalent to $1 \%$ of the body surface area and the total area of the 20 nails is much smaller than the area of the palm, it becomes clear the incidence of NA-PCM is proportionally greater than in the rest of the body. ${ }^{25}$ In Caucasians NA-PCM responds from 1,4 to $2,0 \%$ of all melanomas. ${ }^{26,27}$ In Afro-american population it is more frequente, reaching $20 \%$ of all melanoma. In American indians frequency 
may be even higher $(31 \%){ }^{28-30}$ In no ethnic group the frequency of NA-PCM is as high as in japanese population. In this population, acral melanoma (which includes all NA-PCM) responds for 50 to $77 \%$ of all melanomas. ${ }^{31,32}$.

Early diagnosis of NA-PCM improves prognosis. However, biopsies, essential for correct diagnosis and staging, carry the possibility of permanent dystrophies of the NA. The inherent complexity of surgical procedures in the NA delays great part of melanoma diagnosis in this location, closing the opportunity window for curative treatment. Lesions arousing much suspicion, such as large lesions or lesions causing nail dystrophy, are usually biopsied. However, these are usually associated with more advanced stages and worse prognosis.

Clinically, subungual melanoma (SUM) at initial stages is often characterized as striated melanonychia $(\mathrm{SM})$, defined as dark bands growing in the longitudinally on the nail. Since it is not a pathognomonic NAPCM clinical finding, melanoma associated SM should be differentiated from those of non-malignant etiology. Early differential diagnosis of SM still remains a challenge for dermatologists, even for nails experts (level of evidence B). ${ }^{33}$ Over the years, signs and methods to assist the physician in early diagnosis of NA melanoma of have been sought. Among them are:

a) Clinical examination:

Hutchinson's signal (HS), periungual pigmentation with or without SM, is historically considered as the most important clinical sign to differentiate SUM from benign melanocytic nevi. ${ }^{34,35}$ However, it is not a pathognomonic sign since it is not present in amelanotic melanoma and can be seen in benign conditions such as melanocyte activation and even in benign melanocytic nevi (level of evidence A) ${ }^{36} \mathrm{HS}$ should be differentiated from pseudo-HS (visualization of pigmen- tation in nail bed or matrix due to peri-ungual tissue transparency) that may be present in Bowen's disease and in benign conditions that cause subungual hyperpigmentation..$^{37,38}$ Topical or systemic drugs can also cause SM, which may or may not be associated with the peri-ungual pigmentation. ${ }^{39-42}$

Clinical examination with naked eye was used for decades as the sole diagnostic method. To increase accuracy, ABCDEF rule for SUM was created, like the $\mathrm{ABCD}$ rule for $\mathrm{CM}^{43,44}$ Each letter refers to a characteristic associated with increased risk for SUM, as it is shown in Chart 3.

b) Nail plate dermoscopy:

DMCP plays a key role in PCM early diagnosis, however, this role is less impacting on the evaluation of SM and SUM. It's important to remember that DMCP helps to differentiate melanin and blood (although it cannot differentiate between bleeding caused by tumor). There is no evidence of the superiority of polarized in relation to non-polarized light in the examination of SM. ${ }^{42}$

c) Intraoperative dermoscopy:

The nail plate is translucent and allows dermoscopic visualization of the pigment present in the nail bed, but visual characteristics are altered, making it difficult to reach a correct interpretation. If the nail plate is surgically removed, it is possible to perform direct DMCP on the nail bed using a polarized light dermatoscope.

Studies correlating nail bed DMCP with histological evaluation of SM allowed identifying patterns with high diagnostic accuracy (level of evidence A). ${ }^{43}$ It is important to note that, intraoperative DMCP does not replace histologic examination, which remains the gold standard for diagnosis of SUM and

CHART 3: Meaning of the mnemonic method "ABCDEF" of melanoma of the nail apparatus

\begin{tabular}{|c|c|c|}
\hline Letter & Meaning & Detailing \\
\hline Age & Most affected age and ethnicities & $\begin{array}{l}\text { From } 20 \text { to } 90 \text { years, with peak of incidence between the } 5 \text { th and } 7 \text { th } \\
\text { decades; }\end{array}$ \\
\hline & & African-Americans, Asians and American Indians. \\
\hline Band & Band or stripe & Striation width equal to or greater than $3 \mathrm{~mm}$ \\
\hline Change & Change/ alteration & $\begin{array}{l}\text { Blurred or jagged edges, brown/ black pigment. } \\
\text { Rapid growth in the size of the band; }\end{array}$ \\
\hline Digit & Finger involved & $\begin{array}{l}\text { Absence of recovery (healing) of nail dystrophy despite treatment. } \\
\text { Order of incidence: pollex > hallux > index; single finger }>\text { several } \\
\text { fingers; dominant hand. }\end{array}$ \\
\hline Extension & Extension & $\begin{array}{l}\text { Pigment extension to proximal, lateral or hyponychium nail fold } \\
\text { (Hutchinson's sign). }\end{array}$ \\
\hline Family & Family history & Family/ personnel history of melanoma or dysplastic nevus syndrome. \\
\hline
\end{tabular}


provides crucial data for evaluation of surgical margins, therapy and prognosis (level of evidence B).

Tangential excision, also known as "nail matrix shave biopsy" allows the removal of lesions larger than $3 \mathrm{~mm}$ with minimal risk of scarring the NA, as well as enabling an assessment of safety margin (level of evidence B)..$^{25,42-44}$

Recognizing and biopsying SUM in early stages is key to achieving cure rates similar to those of in situ PCM.

\section{Recommendations:}

- ABCDEF rule provides a methodology for clinical evaluation of SM and increases clinical diagnosis sensitivity of SUM (grade of recommendation A).

- nail plate DMCP increases accuracy for indicating SM biopsies (grade of recommendation A).

- Intraoperative DMCP has high level of accuracy in the correlation between visualized and histological pattern (grade of recommendation A).

- Histologic examination still remains the gold standard for definitive diagnosis of NA melanoma (grade of recommendation $\mathrm{A}$ ).

3) Is there prognostic difference when performing incisional or excisional biopsy of suspected melanoma lesions?

Excisional biopsy (EB) with 1 to $3 \mathrm{~mm}$ margins is recommended as first choice therapy for pigmented lesion suspected of melanoma. EB enables better histological evaluation, which includes: tumor thickness (Breslow depth), MIand presence or absence of ulceration. These 3 items are essential to define staging, prognosis and treatment. ${ }^{45}$ There are situations where EB is difficult to perform, such as, but not only extensive pigmented lesions on the face, mucous membranes or acral lesions or extensive lesions with low suspicion of melanoma. In such cases, incisional biopsy (IB) would be less invasive than EB. ${ }^{46}$

Although IB is technically simpler to perform and has lower cost, a point that should be taken into consideration since healthcare resources are scarce in many countries, it allows only a partial histological evaluation of the lesion. ${ }^{46}$ The concern that mechanical manipulation (such as punch biopsy or needle biopsy) could implant neoplastic cells and increase the risk of metastases was great for many years and IB was contraindicated at that time. This potential risk has been discussed not only for melanoma, but also for various types of tumors. ${ }^{47}$ Presently it is believed this risk has been overestimated and there are considerations that tumor cells molecular characteristics, such as adhesion molecules, matrix metalloproteinase and vascular growth factors, may influence the ability to migrate and to induce vascularization, which would be more important in disseminating tumor cells than just mechanical manipulation. ${ }^{48}$

To assess whether IB resulted in worse prognosis compared to EB, several retrospective and prospective studies were conducted. ${ }^{49-57}$ Most of them, especially those with larger numbers of patients, showed that the type of biopsy does not play a role in the evolution of melanoma patients (level of evidence A).

IB can be performed by shave, punch or incisional techniques. A study comparing histological evaluation of EB, shave biopsy, punch biopsy and IB, showed that treatment recommendations changed in $6 \%$ of the cases: ( $2 \%$ after EB, $5 \%$ after shave biopsy, $18 \%$ after punch biopsy and $18 \%$ after IB). Thus, it was found that EB allows better histological evaluation and should be preferred whenever possible (level of evidence A). ${ }^{58}$

A prospective study designed to evaluate the impact on staging, area of margins expansion, sentinel node positivity, tumor recurrence and survival evaluated 709 patients who underwent punch biopsy (23\%), shave biopsy (34\%) and EB (43\%). There was no significant difference in accuracy of sentinel lymph node results, tumor recurrence nor in patient survival. The study concluded that biopsy type did not impact SLNB accuracy or results, tumor recurrence, or prognosis. Punch and shave biopsies, when used appropriately, should not be discouraged for the diagnosis of melanoma (level of evidence A). ${ }^{59}$

IB may be used for lesions suspected of melanoma located in areas where EB is difficult to perform, such as - but not limited to - large lesions, lesions located on the face, mucous membranes and acral regions or lesions with low probability of melanoma (level of evidence B). ${ }^{46}$

When deciding on IB, it must be performed in locations that allow histological evaluation of the greater depth of the lesion (clinically darker areas and/or papular). DMCP can be a useful tool for selecting the best place for biopsy, but there are still no studies with large number of patients that support this recommendation (level of evidence D). ${ }^{60}$

\section{Recommendations:}

- EB should be the preferred technique whenever possible, because it allows better tumor histological evaluation, which directly impacts in the conduct and prognosis (grade of recommendation $\mathrm{A}$ ).

- IB does not affect prognosis of melanoma patients and can be used when necessary (grade of recommendation A).

- IB is suggested in the following cases, but is not limited to (grade of recommendation B):

- Extensive pigmented lesions with low suspicion of melanoma; 
- Suspected extensive lentigo maligna on the face;

- Suspicious pigmented lesions, extensive or in an acral region;

- Mucosal lesions.

- The major axis of the biopsy should be oriented so as to facilitate possible margins expansion. In general, when performed in the members it means along the major axis (grade of recommendation C).

4) Does the review of histological findings by a pathologist trained in melanoma contribute to the diagnosis and treatment of PCM?

The gold-standard for PCM diagnosis is histopathology. Roughly, there exist about 20 histological items to be evaluated in each case before a final diagnosis is rendered. This is a challenging task, which can be influenced by interpretation biases ${ }^{61}$. Experience and interest of general pathologists on this issue are heterogeneous, as is the frequency such a neoplasm is found in diagnostic routine in general pathology laboratories.

In addition to correct diagnosis, it is essential that histologic reports on melanoma address microstaging (MST) items, which will be essential for determining treatment and prognosis ${ }^{62}$. Since appropriate local treatment and the decision of performing sentinel lymphnode biopsy rely on MST items, histologic report must include at least the following data ${ }^{8,62-68}$ :

1. Margin involvement and margin distances from the neoplasm;

2. Presence or not of dermal invasion;

3. In invasive neoplasms:

a. Tumor thickness (Breslow depth);

b. Mitotic index (MI);

c. Ulceration: present or not;

d. Microsatellitosis / satellitosis.

Studies have shown that information on MI, ulceration, microsatellitosis and tumor thickness are not originally included in melanoma histologic reports in $47-50 \%, 13-72 \%, 50 \%$, and $29 \%$ of cases, respectively. ${ }^{69-71}$ In order to reduce such frequencies, some of the most influential pathology societies worldwide created a consensus protocol on mandatory and wishful items to be included in melanoma histologic reports. ${ }^{66}$

Correct histological criteria to determine dermal invasion, ulceration, and microsatellitosis, as well as proper methodology for measuring Breslow thickness and mitotic counting are of equal importance. ${ }^{66-66}$

Physicians reading melanoma histologic reports cannot directly check if proper methodology for each item was used correctly in a given case. The only practical way to achieve this goal is to request a second opinion to a pathologist with expertise in melanoma or to send the slides to a melanoma referral hospital for histopathological review.

Indeed, a recent study has shown that review of thin and in situ melanomas by an expert pathologist has led to changes in diagnosis and microstaging with subsequent modification of original proposed local treatment and SLNB in $12 \%$ and $16 \%$, respectively. (Level of evidence B). ${ }^{69}$ Similarly, a retrospective large series showed that margin status was modified in $11 \%$ of cases after expert review. ${ }^{72}$

It has been shown that reporting of Breslow thickness, MI, and ulceration has good inter-observer reproducibility among pathologists. ${ }^{73-76}$ On the other hand, microsatellitosis remains a microstaging item of low reproducibility. ${ }^{75}$ This data seems very important because the detection of microsatellitosis in primary melanoma resection (or biopsy) specimen modifies pathologic staging from $\mathrm{pN} 0$ (or $\mathrm{pNx}$ ) to $\mathrm{pN} 2 \mathrm{c}$. $8,68,69$

With regard to differential diagnoses of melanocytic nevus versus melanoma, studies report that reproducibility ranges from $73 \%$ to $97.3 \%$ between general and expert pathologists. ${ }^{72,75-78}$ It has also been known for a long time that ambiguous melanocytic lesions can lead to diagnostic disagreement even among experts. ${ }^{79}$ Examples of ambiguous lesions include atypical nevus with severe cytological and architectural atypia, atypical Spitz tumors, etc. Advances in genetics knowledge have brought profound changes in the understanding of these ambiguous lesions. As a result, the polarization "melanocytic nevus (benign) versus melanoma (malignant)" has progressively given way to the recognition of a range of intermediate lesions categorized as low-grade malignant or of uncertain biological behavior. Although such lesions do not constitute a clinicopathological entity, they form a spectrum with intermediate morphological and genetic aberrations lying between classical nevi and melanomas. As a group, these lesions have the potential to evolve with microscopic regional lymphnode metastases, but they rarely lead patients to death 80. Examples of such lesions include atypical Spitz tumors, atypical blue nevi, and melanocytoma (also known as epithelioid blue nevus. which presents some overlap with animal-type melanoma, according to some authors) ${ }^{80-82}$.

Great effort of the scientific community has been made to stratify this intermediary group of lesions by fluorescent in situ hybridization (FISH) so that lesions with higher probability of aggressive behavior may be detected and managed accordingly, particularly atypical Spitz tumors (level of evidence B) ${ }^{83}$. Immunohistochemistry, FISH, and other molecular pathology techniques have been used in order to reduce subjectivity of morphological examination of 
ambiguous cases (level of evidence B) ${ }^{84-87}$.

\section{Recommendations:}

- Definite diagnosis of melanoma is based on histopathology of excision or biopsy specimens (level of recommendation A);

- Melanoma histologic report must include histological items of MST (level of recommendation A).

- Histological review by an expert pathologist/ melanoma referral center should be sought whenever possible before definitive treatment (level of recommendation B).

- Immunohistochemistry and molecular studies can be used to aid in the diagnosis of selected cases of ambiguous melanocytic lesions (level of recommendation $B$ ).

\section{5) What margin should lentigo maligna mela- noma and melanoma in situ be excised with?}

The primary treatment for PCM is surgical resection. ${ }^{88,89}$ Historically, through the 20th century, resection with circumferential margin of 3-5 mm was indicated for PCM of any thickness, followed by grafting. Rationale was based on the occurrence of "centrifugal lymphatic spread", seen in histological preparations of excised melanomas. ${ }^{90}$

Current recommendation is that smaller margins are used, reducing surgery morbidity. This is based on prospective studies comparing more conservative with more radical surgeries, on randomized studies and on international consensus conferences. ${ }^{91-103}$ These studies demonstrated that histological findings will determine the appropriate surgical margins, and the Breslow thickness is the most important data (level of evidence A).

It is important to remember that for both in situ and invasive melanomas, histological examination with paraffin embedded sections is the gold standard for evaluation of surgical margins and that margins expansion surgery should be performed preferably between 4 to 6 weeks from the initial biopsy (level of evidence C). ${ }^{100}$

Margins recommended for PCM surgical excision appear below (Table 1 ).

There is no consensus regarding deep margins resection as it occurs for lateral margins. Historically, the recommendation is that invasive PCM is resected until the muscle fascia. There is, however, no evidence confirming that such action is necessary in all cases. A group of experts recommends that, whenever possible, resection is made to the fascia or to the deep subcutaneous tissue, depending on tumor location (level of evidence B).

Although surgical resection is the standard treatment for in situ melanoma (is M) and for LM, scientific evidences regarding the surgical margins to be used are not as clear as for invasive melanomas. This is because it is known that large is $\mathrm{M}, \mathrm{LM}$ and lentigo maligna melanoma (LMM) often present subclinical atypical junctional hyperplasia in peripheral and peri-adnexal areas of the lesion, which can extend for several millimeters beyond the visible margins. ${ }^{45,101-103}$

Several authors agree that $5 \mathrm{~mm}$ margins may often be insufficient. Many studies have shown that up to $20 \%$ of LM require margins larger than $5 \mathrm{~mm}$, while $12 \%$ of LMM with Breslow thickness up to 1.0 $\mathrm{mm}$ require margins with more than $10 \mathrm{~mm}$ (level of evidence B). ${ }^{104}$ According to Kunishige et al, $9 \mathrm{~mm}$ margins would be sufficient in $99 \%$ of cases (level of evidence B). ${ }^{105}$

It is also known that recurrent LM and LMM tend to require wider margins (level of evidence B). The lack of prospective studies suggests that, in the cases of large is M, LM and LMM, the determination of the margins is defined by consensus of expert groups or by retrospective studies (level of evidence B).

The usefulness of the various methods of micrographic control of margins is very discussed. ${ }^{45,101,103}$ The most disseminated is Mohs' method, but several other methods of margins micrographic control appear in the literature, with different nomenclatures

TABLE 1: Surgical Margins for the treatment of primary cutaneous melanoma

\begin{tabular}{lcc}
\hline Breslow thickness $(\mathrm{mm})$ & Surgical margin $(\mathrm{cm})$ & Level of evidence \\
In situ & $0.5 \#$ & A \\
Up to 1.00 & 1.0 & A \\
From 1.01 to 2.00 & 1.0 to $2.0 *$ & B \\
More than 2.00 & 2.0 & A \\
\hline
\end{tabular}

t-test

* The surgical margins can be modified to contemplate anatomical, functional or aesthetic needs. Experts agree that margins between $1 \mathrm{~cm}$ and $2 \mathrm{~cm}$ are acceptable in areas where margins of $2 \mathrm{~cm}$ would cause significant aesthetic, functional or anatomical losses. The patient should be informed and agree with the doctor about the best option. 
such as 3D histology method, Tubingen pie chart, staged surgical excision, etc. Micrographic surgery is a very useful method to treat lesions in areas where healthy tissue preservation is important, such as the face, as well as to allow greater surgical margins control. It also diminishes the risk of recurrence and may reduce the final size of surgical wounds (level of evidence C). ${ }^{45,101,104,106}$

At this point it is important to remember that histological examination by conventional frozen sections are not suitable for determining surgical margins of melanocytic lesions (level of evidence A). The ideal is to examine paraffin sections. Advances in IHC techniques towards melanocytes identification will allow frozes sections to achieve higher reliability rates. ${ }^{107-111}$

Some authors recommend the use of Wood's light to assist in assessing the real extent of the tumor (level of evidence D). ${ }^{112}$

Use of alternative non-surgical therapeutic methods for treating LM or is M, (imiquimod and radiation) are justified in cases where surgery can cause great aesthetic/ functional damage or in patients unable to undergo surgery. ${ }^{45,104}$ Literature presents reports of complete response of up to $88 \%$ of cases, but it is important to consider that it is not possible to obtain a complete histological analysis of the lesion, thus eventual invasive melanoma foci would not be identified. Histological examination after treatment showed persistence of disease in up to $25 \%$ of treated patients and there were cases of LM progression to invasive melanoma. Moreover, diversity of therapeutic regimens and short monitoring period limit the comparative studies (level of evidence C). ${ }^{101}$

Cryosurgery with liquid nitrogen has not been adequately studied, but it's one more option. There are no comparative long-term studies on the subject (level of evidence D). ${ }^{101}$

\section{Recommendation}

- $\quad$ For patients with isM, surgical margins of 0.5 $\mathrm{cm}$ are sufficient (grade of recommendation B).

- Treatment margins for large isM / LM are at least $0.5 \mathrm{~cm}$, and it may be necessary to increase them (grade of recommendation A).

- The use of micrographic surgery techniques for large isM, LM and LMM can assist in more accurate determination of surgical margins, but paraffin sections should be used and, when available, IHC techniques (grade of recommendation B).

- Use of imiquimod to treat LM or isM, although off-label, is justified in cases where surgery can cause great aesthetic/ functional impairment or in patients unable to undergo surgery. Because data for these situations are limited, the surgeon must make the decision with the patient (grade of recommendation C).

At the end of this first part of the Brazilian guidelines on melanoma, it is extremely important to point out that they are not intended to stifle medical practice, but to make it more homogeneous, reducing uncertainty/ disagreement on good practice standards. Stablishing standards, besides reducing the differences in patient care, can also make possible to provide options based on evidence, allowing the physician to make decisions about treatment or diagnostic methods, thus reducing the strain on patients, doctors and on the healthcare system.

These guidelines reflect the best scientific information published about the subject to the date of its preparation. Nevertheless, we must be careful when interpreting these data, since the outcome of future studies can lead to changes in recommendations. In some cases, it may be necessary not to follow these guidelines, always keeping in mind patients` well-being, as well as other special circumstances.

\section{ACKNOWLEDGEMENTS}

To the staff of the Brazilian Society of Dermatology library, directed by librarian Vanessa Zampier and Rosalynn Leite. 


\section{REFERENCES}

1. Tovo FLR, Belfort FA, Sanches Jr JA. Melanoma cutâneo - Abordagem da lesão primária. Acta Oncol Bras. 2003;23:454-8.

2. Agencia Nacional de Saúde Suplementar. Associação Medica Brasileira. Conselho Federal de Medicina 0 processo de elaboração, validação e implementação das diretrizes clinicas na saúde suplementar no Brasil. Rio de Janeiro: ANS; 2009. $78 \mathrm{p}$.

3. Friedman RJ, Rigel DS, Kopf AW. Early detection of malignant melanoma: the role of physician examination and self-examination of the skin. CA Cancer J Clin. 1985;35:130-51.

4. Robinson JK, Turrisi R. Skills training to learn discrimination of ABCDE criteria by those at risk of developing melanoma. Arch Dermatol. 2006;142:447-52.

5. Abbasi NR, Shaw HM, Rigel DS, Friedman RJ, McCarthy WH, Osman I, et al. Early diagnosis of cutaneous melanoma: revisiting the ABCD criteria. JAMA. 2004;292:2771-6.

6. Kittler H, Pehamberger $\mathrm{H}$, Wolff K, Binder M. Diagnostic accuracy of dermoscopy. Lancet Oncol. 2002;3:159-65.

7. Vestergaard ME, Macaskill P, Holt PE, Menzies SW. Dermoscopy compared with naked eye examination for the diagnosis of primary melanoma: a meta-analysis of studies performed in a clinical setting. Br J Dermatol. 2008;159:669-76.

8. Menzies SW. Evidence-based dermoscopy. Dermatol Clin. 2013;31:521-4, vii.

9. Nachbar F, Stolz W, Merkle T, Cognetta AB, Vogt T, Landthaler M, et al. The $A B C D$ rule of dermatoscopy. High prospective value in the diagnosis of doubtful melanocytic skin lesions. J Am Acad Dermatol. 1994;30:551-9.

10. Argenziano G, Soyer HP, Chimenti S, Talamini R, Corona R, Sera F, et al. Dermoscopy of pigmented skin lesions: results of a consensus meeting via the Internet. J Am Acad Dermatol. 2003;48:679-93.

11. Westerhoff K, McCarthy WH, Menzies SW. Increase in the sensitivity for melanoma diagnosis by primary care physicians using skin surface microscopy. Br J Dermatol. 2000;143:1016-20.

12. Argenziano G, Fabbrocini G, Carli P, De Giorgi V, Sammarco E, Delfino M. Epiluminescence microscopy for the diagnosis of doubtful melanocytic lesions. Comparison of the ABCD rule of dermatoscopy and a new 7-point checklist based on pattern analysis. Arch Dermatol. 1998;134:1563-70.

13. Dolianitis C, Kelly J, Wolfe R, Simpson P. Comparative performance of 4 dermoscopic algorithms by nonexperts for the diagnosis of melanocytic lesions. Arch Dermatol. 2005;141:1008-14.

14. Carli P, de Giorgi V, Chiarugi A, Nardini P, Weinstock MA, Crocetti E, et al. Addition of dermoscopy to conventional naked-eye examination in melanoma screening: a randomized study. J Am Acad Dermatol. 2004;50:683-9.

15. Menzies SW, Zalaudek I. Why perform dermoscopy? The evidence for its role in the routine management of pigmented skin lesions. Arch Dermatol. 2006;142:1211-2.

16. Carli P, De Giorgi V, Crocetti E, Mannone F, Massi D, Chiarugi A, et al. Improvement of malignant/benign ratio in excised melanocytic lesions in the 'dermoscopy era': a retrospective study 1997-2001. Br J Dermatol. 2004;150:687-92.

17. van der Rhee Jl, Bergman W, Kukutsch NA. The impact of dermoscopy on the management of pigmented lesions in everyday clinical practice of general dermatologists: a prospective study. Br J Dermatol. 2010;162:563-7.

18. Moulin C, Poulalhon N, Duru G, Debarbieux S, Dalle S, Thomas L. Dermoscopy use by French private practice dermatologists: a nationwide survey. Br J Dermatol. 2013;168:74-9.

19. Binder M, Schwarz M, Winkler A, Steiner A, Kaider A, Wolff K, et al. Epiluminescence microscopy. A useful tool for the diagnosis of pigmented skin lesions for formally trained dermatologists. Arch Dermatol. 1995;131:286-91.

20. Piccolo D, Ferrari A, Peris K, Diadone R, Ruggeri B, Chimenti S. Dermoscopic diagnosis by a trained clinician vs a clinician with minimal dermoscopy training vs computer-aided diagnosis of 341 pigmented skin lesions: a comparative study. $\mathrm{Br}$ J Dermatol. 2002;147:481-6.

21. Noor 0 2nd, Nanda A, Rao BK. A dermoscopy survey to assess who is using it and why it is or is not being used. Int J Dermatol. 2009;48:951-2.

22. Wu TP, Newlove T, Smith L, Vuong CH, Stein JA, Polsky D. The importance of dedicated dermoscopy training during residency: a survey of US dermatology chief residents. J Am Acad Dermatol. 2013;68:1000-5.

23. Finley RK 3rd, Driscoll DL, Blumenson LE, Karakousis CP. Subungual melanoma: an eighteen-year review. Surgery. 1994;116:96-100.

24. Quinn MJ, Thompson JE, Crotty K, McCarthy WH, Coates AS. Subungual melanoma of the hand. J Hand Surg Am. 1996;21:506-11.

25. Haneke E. Ungueal melanoma - controversies in diagnosis and treatment. Dermatol Ther. 2012;25:510-24.

26. Banfield CC, Redburn JC, Dawber RP. The incidence and prognosis of nail apparatus melanoma. A retrospective study of 105 patients in four English regions. Br J Dermatol. 1998;139:276-9.

27. O'Leary JA, Berend KR, Johnson JL, Levin LS, Seigler HF. Subungual melanoma. A review of 93 cases with identification of prognostic variables. Clin Orthop Relat
Res. 2000;378:206-12.

28. Baran R, Kechijian P. Longitudinal melanonychia (melanonychia striata): diagnosis and management. J Am Acad Dermatol. 1989;21:1165-75.

29. Thai KE, Young R, Sinclair RD. Nail apparatus melanoma. Australas J Dermatol. 2001;42:71-81

30. Black WC, Wiggins C. Melanoma among southwestern American Indians. Cancer 1985;55:2899-902

31. Seui M, Takematsu H, Hosokawa M, Obata M, Tomita Y, Kato T, et al. Acral melanoma in Japan. J Invest Dermatol. 1983;80:56s-60s

32. Ishihara K, Saida T, Otsuka F, Yamazaki N; Prognosis and Statistical Investigation Committee of the Japanese Skin Cancer Society. Statistical profiles of malignant melanoma and other skin cancers in Japan: 2007 update. Int J Clin Oncol. 2008:13:33-41.

33. Di Chiacchio N, Hirata SH, Enokihara MY, Michalany NS, Fabbrocini G, Tosti A. Dermatologists' accuracy in early diagnosis of melanoma of the nail matrix. Arch Dermatol. 2010:146:382-7.

34. Fitzpatrick TB, Eisen AZ, Wolff K, Freedberg IM, Austen KF. Dermatology in genera medicine. 7th ed. McGraw-Hill: New York; 2008.

35. Saida T, Ohshima Y. Clinical and histopathologic characteristics of early lesions of subungual malignant melanoma. Cancer. 1989;63:556-60.

36. Kawabata Y, Ohara K, Hino H, Tamaki K. Two kinds of Hutchinson's sign, benign and malignant. J Am Acad Dermatol. 2001;44:305-7.

37. Baran R Kechijian P. Hutchinson's sign: a reappraisal. J Am Acad Dermatol. 1996:34:87-90.

38. Braun RP, Baran R, Le Gal FA, Dalle S, Ronger S, Pandolfi R, et al. Diagnosis and management of nail pigmentations. J Am Acad Dermatol. 2007;56:835-47.

39. Mooney E, Bennett RG. Periungual hyperpigmentation mimicking Hutchinson's sign associated with minocycline administration. J Dermatol Surg Oncol. 1988;14:1011-3

40. Levit EK, Kagen MH, Scher RK, Grossman M, Altman E. The ABC rule for clinica detection of subungual melanoma. J Am Acad Dermatol. 2000;42:269-74

41. Tan KB, Moncrieff M, Thompson JF, McCarthy SW, Shaw HM, Quinn MJ, et al. Subungual melanoma: a study of 124 cases highlighting features of early lesions, potential pitfalls in diagnosis, and guidelines for histologic reporting. Am J Surg Pathol. 2007;31:1902-12.

42. Di Chiacchio ND, Farias DC, Piraccini BM, Hirata SH, Richert B, Zaiac M, et al. Consensus on melanonychia nail plate dermoscopy. An Bras Dermatol. 2013:88:309-13.

43. Hirata SH, Yamada S, Enokihara MY, Di Chiacchio N, de Almeida FA, Enokihara $\mathrm{MM}$, et al. Patterns of nail matrix and bed of Iongitudinal melanonychia by intraoperative dermatoscopy. J Am Acad Dermatol. 2011;65:297-303.

44. Di Chiacchio N, Loureiro WR, Michalany NS, Kezam Gabriel FV. Tangential Biopsy Thickness versus Lesion Depth in Longitudinal Melanonychia: A Pilot Study Dermatol Res Pract. 2012;2012:353864

45. Coit DG, Andtbacka R, Anker CJ, Bichakjian CK, Carson WE 3rd, Daud A, et al. Melanoma,version2.2013: featured updates to the NCCN guidelines. J Natl Comp Canc Netw. 2013;11:395-407.

46. Pflugfelder A, Weide B, Eigentler TK, Forschner A, Leiter U, Held L, et al. Incisiona biopsy and melanoma prognosis: facts and controversies. Clin Dermatol. 2010;28:316-8

47. Fentiman IS, Millis RR, Chaudary MA, King RJ, Miller KJ, Hayward JL. Effect of the method of biopsy on prognosis and reliability of receptor assays in patients with operable breast cancer. Br J Surg. 1986;73:610-2.

48. Evan Gl, Vousden KH. Proliferation, cell cycle and apoptosis in cancer. Nature 2001:411:342-8.

49. Molenkamp BG, Sluijter BJ, Oosterhof B, Meijer S, van Leeuwen PA. Non-radical diagnostic biopsies do not negatively influence melanoma patient survival. Ann Surg Oncol. 2007:14:1424-30.

50. Martin RC 2nd, Scoggins CR, Ross MI, Reintgen DS, Noyes RD, Edwards MJ et al. Is incisional biopsy of melanoma harmful? Am J Surg. 2005;190:913-7.

51. Bong JL, Herd RM, Hunter JA. Incisional biopsy and melanoma prognosis. J Am Acad Dermatol. 2002:46:690-4.

52. Austin JR, Byers RM, Brown WD, Wolf P. Influence of biopsy on the prognosis of cutaneous melanoma of the head and neck. Head Neck. 1996;18:107-17.

53. Lees VC, Briggs JC. Effect of initial biopsy procedure on prognosis in stage invasive cutaneous malignant melanoma: review of 1086 patients. $\mathrm{Br} \mathrm{J}$ Surg 1991;78:1108-10.

54. Lederman JS, Sober AJ. Does biopsy type influence survival in clinical stage cutaneous melanoma? J Am Acad Dermatol. 1985;13:983-7.

55. Griffiths RW, Briggs JC. Biopsy procedures, primar y wide excisional surgery and long term prognosis in primary clinical stage I invasive cutaneous malignant melanoma. Ann R Coll Surg Engl. 1985;67:75-8

56. Rampen FH, van Houten WA, Jop WC. Incisional procedures and prognosis in malignant melanoma. Clin Exp Dermatol. 1980;5:313-20. 
57. Epstein $\mathrm{E}$, Bragg K, Linden G. Biopsy and prognosis of malignant melanoma. JAMA. 1969;208:1369-71.

58. Hieken TJ, Hernández-Irizarry R, Boll JM, Jones Coleman JE. Accuracy of diagnostic biopsy for cutaneous melanoma: implications for surgical oncologists. Int J Surg Oncol. 2013;2013:196493.

59. Mills JK, White I, Diggs B, Fortino J, Vetto JT. Effect of biopsy type on outcome in the treatment of primary cutaneous melanoma. Am J Surg. 2013;205:585-90.

60. Bomm L, Benez MD, Maceira JM, Succi IC, Scotelaro Mde F. Biopsy guided by dermoscopy in cutaneous pigmented lesion - case report. An Bras Dermatol. 2013;88:125-7

61. Scolyer RA, Prieto VG. Melanoma pathology: important issues for clinicians involved in the multidisciplinary care of melanoma patients. Surg Oncol Clin N Am. 2011:20:19-37.

62. Balch CM, Gershenwald JE, Soong SJ, Thompson JF, Atkins MB, Byrd DR, et al. Final version of 2009 AJCC melanoma staging and classification. J Clin Oncol. 2009:27:6199-206.

63. Cap.org [Internet]. Protocol for the examination of specimens from patients with melanoma of the skin. College of American Pathologists, 2013. [cited 2014 Jun 30]. Available from: http://www.cap.org/apps/docs/committees/cancer/ cancer protocols/2013/SkinMelanoma 13protocol 3300.pdf.

64. Rcpa.edu.au [Internet]. Primary cutaneous melanoma structured reporting protocol. 2nd ed. Royal College of Pathologists of Australasia, 2013. [cited 2014 Jun 30]. Available from: http://www.rcpa.edu.au/getattachment/5961bf31-198d4eb0-a0f3-1cdf868a26ac/Protocol-primary-cutaneous-melanoma.aspx.

65. Repath.org [Internet]. Dataset for the histopathological reporting of primary cutaneous malignant melanoma and regional lymph nodes. 3rd ed. Royal College of Pathologists, 2014. [cited 2014 Jun 30]. Available from: http://www.rcpath.org/ publications-media/publications/datasets.

66. Scolyer RA, Judge MJ, Evans A, Frishberg DP, Prieto VG, Thompson JF, et al. International Collaboration on Cancer Reporting. Dataset for pathology reporting of cutaneous invasive melanoma: recommendations from the international collaboration on cancer reporting (ICCR). Am J Surg Pathol. 2013;37:1797-814.

67. Bacchi CE, Melo CRA, de Franco MF, Artigiani Neto R. Manual de Padronização de Laudos Histopatológicos. Sociedade Brasileira de Patologia. 4. ed. Barueri (SP): Manole; 2014. Capítulo 1, Melanoma; p.1-12.

68. Dummer R, Hauschild A, Guggenheim M, Keilholz U, Pentheroudakis G; ESMO Guidelines Working Group. Cutaneous melanoma: ESMO Clinical Practice Guidelines for diagnosis, treatment and follow-up. Ann Oncol. 2012;23:vii86-91.

69. Santillan AA, Messina JL, Marzban SS, Crespo G, Sondak VK, Zager JS. Pathology review of thin melanoma and melanoma in situ in a multidisciplinary melanoma clinic: impact on treatment decisions. J Clin Oncol. 2010;28:481-6.

70. Thompson B, Austin R, Coory M, Aitken JF, Walpole E, Francis G, et al. Completeness of histopathology reporting of melanoma in a high-incidence geographical region. Dermatology. 2009;218:7-14.

71. Busam KJ. Lack of relevant information for tumor staging in pathology reports of primary cutaneous melanoma. Am J Clin Pathol. 2001;115:743-6.

72. Niebling MG, Haydu LE, Karim RZ, Thompson JF, Scolyer RA. Pathology review significantly affects diagnosis and treatment of melanoma patients: an analysis of 5011 patients treated at a melanoma treatment center. Ann Surg Oncol. 2014;21:2245-51

73. Scolyer RA, Shaw HM, Thompson JF, Li LX, Colman MH, Lo SK, et al. Interobserver reproducibility of histopathologic prognostic variables in primary cutaneous melanomas. Am J Surg Pathol. 2003;27:1571-6.

74. Niebling MG, Haydu LE, Karim RZ, Thompson JF, Scolyer RA. Reproducibility of AJCC staging parameters in primary cutaneous melanoma: an analysis of 4.924 cases. Ann Surg Oncol. 2013:20:3969-75.

75. Monshizadeh L, Hanikeri M, Beer TW, Heenan PJ. A critical review of melanoma pathology reports for patients referred to the Western Australian Melanoma Advisory Service. Pathology. 2012;44:441-7.

76. Shoo BA, Sagebiel RW, Kashani-Sabet M. Discordance in the histopathologic diagnosis of melanoma at a melanoma referral center. J Am Acad Dermatol. 2010;62:751-6.

77. McGinnis KS, Lessin SR, Elder DE, Guerry D 4th, Schuchter L, Ming M, et al. Pathology review of cases presenting to a multidisciplinary pigmented lesion clinic. Arch Dermatol. 2002:138:617-21.

78. van Dijk MC, Aben KK, van Hees F, Klaasen A, Blokx WA, Kiemeney LA, LA et al. Expert review remains important in the histopathological diagnosis of cutaneous melanocytic lesions. Histopathology. 2008;52:139-46.

79. Farmer ER, Gonin R, Hanna MP. Discordance in the histopathologic diagnosis of melanoma and melanocytic nevi between expert pathologists. Hum Pathol. 1996:27:528-31.

80. Cerroni L, Barnhill R, Elder D, Gottlieb G, Heenan P, Kutzner H, et al. Melanocytic tumors of uncertain malignant potential: results of a tutorial held at the XXIX Symposium of the International Society of Dermatopathology in Graz, October
2008. Am J Surg Pathol. 2010;34:314-26

81. Gerami P, Busam K, Cochran A, Cook MG, Duncan LM, Elder DE, et al. Histomorphologic Assessment and Interobserver Diagnostic Reproducibility of Atypical Spitzoid Melanocytic Neoplasms With Long-term Follow-up. Am J Surg Pathol. 2014;38:934-40.

82. Mandal RV, Murali R, Lundquist KF, Ragsdale BD, Heenan P, McCarthy SW, et al. Pigmented epithelioid melanocytoma: favorable outcome after 5year follow-up Am J Surg Pathol. 2009;33:1778-82.

83. Gerami P, Scolyer RA, Xu X, Elder DE, Abraham RM, Fullen D, et al. Risk assessment for atypical spitzoid melanocytic neoplasms using FISH to identify chromosomal copy number aberrations. Am J Surg Pathol. 2013:37:676-84.

84. Tetzlaff MT, Wang WL, Milless TL, Curry JL, Torres-Cabala CA, McLemore MS, et al. Ambiguous melanocytic tumors in a tertiary referral center: the contribution of fluorescence in situ hybridization (FISH) to conventional histopathologic and immunophenotypic analyses. Am J Surg Pathol. 2013;37:1783-96

85. Bastian BC, LeBoit PE, Hamm H, Bröcker EB, Pinkel D. Chromosomal gains and losses in primary cutaneous melanomas detected by comparative genomic hybridization Cancer Res. 1998;58:2170-5.

86. Gerami P, Jewell SS, Morrison LE, Blondin B, Schulz J, Ruffalo T, et al. Fluorescence in situ hybridization (FISH) as an ancillary diagnostic tool in the diagnosis of melanoma. Am J Surg Pathol. 2009;33:1146-56.

87. North JP, Garrido MC, Kolaitis NA, LeBoit PE, McCalmont TH, Bastian BC Fluorescence in situ hybridization as an ancillary tool in the diagnosis of ambiguous melanocytic neoplasms: a review of 804 cases. Am J Surg Pathol. 2014;38:824-31.

88. Saiag P, Bosquet L, Guillot B, Verola O, Avril MF, Bailly C, et al. Management of adult patients with cutaneous melanoma without distant metastasis.2005 update of the French Standards, Options and Recommendations guidelines. Summary report. Eur J Dermatol. 2007;17:325-31.

89. Hauschild A, Rosien F, Lischner S. Surgical standards in the primary care of melanoma patients. Onkologie. 2003:26:218-22.

90. Handley WS. The pathology of melanotic growths in relation to their operative treatment. Lancet. 1907:1:927-96.

91. Khayat D, Rixe O, Martin G, Soubrane C, Banzet M, Bazex JA, et al. French Group of Research on Malignant Melanoma. Surgical margins in cutaneous melanoma $(2 \mathrm{~cm}$ versus $5 \mathrm{~cm}$ for lesions measuring less than $2.1-\mathrm{mm}$ thick). Cancer. 2003;97:1941-6.

92. Ringborg U, Andersson R, Eldh J, Glaumann B, Hafström L, Jacobsson S, et al. Resection margins of 2 versus $5 \mathrm{~cm}$ for cutaneous malignant melanoma with a tumor thickness of 0.8 to 2.0. mm: randomized study by the Swedish Melanoma Study Group. Cancer. 1996;77:1809-14.

93. Cohn-Cedermark G, Rutqvist LE, Andersson R, Breivald M, Ingvar C, Johansson $\mathrm{H}$, et al. Long term results of a randomized study by the Swedish Melanoma Study Group on 2-cm versus 5-cm resection margins for patients with cutaneous melanoma with a tumor thickness of 0.8-2.0 mm. Cancer. 2000:89:1495-501.

94. Veronesi U, Cascinelli N, Adamus J, Balch C, Bandiera D, Barchuk A, et al. Thin stage I primary cutaneous malignant melanoma. Comparison of excision with margins of 1 or $3 \mathrm{~cm}$. N Engl J Med. 1988;318:1159-62.

95. Veronesi U, Cascinelli N. Narrow excision (1-cm margin). A safe procedure for thin cutaneous melanoma. Arch Surg. 1991;126:438-41.

96. Cascinelli N. Margin of resection in the management of primary melanoma. Semin Surg Oncol. 1998;14:272-5.

97. Balch CM, Urist MM, Karakousis CP, Smith TJ, Temple WJ, Drzewiecki K, et al. Efficacy of 2-cm surgical margins for intermediate-thickness melanomas (1 to $4 \mathrm{~mm}$ ). Results of a multi-institutional randomized surgical trial. Ann Surg 1993:218:262-7.

98. Karakousis CP, Balch CM, Urist MM, Ross MM, Smith TJ, Bartolucci AA. Local recurrence in malignant melanoma: long-term results of the multi institutional randomized surgical trial. Ann Surg Oncol. 1996;3:446-52.

99. Thomas JM, Newton-Bishop J, A'Hern R, Coombes G, Timmons M, et al. Excision margins in high-risk malignant melanoma. N Engl J Med. 2004;350:757-66.

100. Garbe C, Hauschild A, Volkenandt M, Schadendorf D, Stolz W, Reinhold U, et al. Evidence and interdisciplinary consensus-based German guidelines: surgical treatment and radiotherapy of melanoma. Melanoma Res. 2008;18:61-7.

101. Marsden JR, Newton-Bishop JA, Burrows L, Cook M, Corrie PG, Cox NH, et al. Revised U.K. guidelines for the management of cutaneous melanoma 2010. Br J Dermatol. 2010;163:238-56.

102. Cancer Council Australia., Ministry of Health.; Melanoma Network (N.S.W.); Cancer Institute NSW., New Zealand Guidelines Group. Clinical Practice Guidelines for the Management of Melanoma in Australia and New Zealand: Evidence-based Best Practice Guidelines. Sydney, N.S.W. : Cancer Council Australia: Ministry of Health, 2008.

103. Négrier S, Saiag P, Guillot B, Verola O, Avril MF, Bailly C, et al. Guidelines for clinical practice. Standards, options and Recommendations 2005 for the management 
of adult patients exhibiting an M0 cutaneous melanoma, full report. national Federation of Cancer Campaign Centers. French Dermatology Society. Update of the 1995 consensus Conference and the 1998 standards, options, and recommendations. Ann Dermatol Venereol. 2005;132:10S3-10S85.

104. Erickson C, Miller SJ. Treatment options in melanoma in situ: topical and radiation therapy, excision and Mohs surgery. Int J Dermatol. 2010;49:482-91.

105. Kunishige JH, Brodland DG, Zitelli JA. Surgical margins for melanoma in situ. J Am Acad Dermatol. 2012;66:438-44.

106. Möhrle M.J Micrographic controlled surgery (3D-histology) in cutaneous melanoma. J Dtsch Dermatol Ges. 2003;1:869-75.

107. Chang KH, Finn DT, Lee D, Bhawan J, Dallal GE, Rogers GS. Novel 16-minute technique for evaluating melanoma resection margins during Mohs surgery. J Am Acad Dermatol. 2011;64:107-12

108. Kimyai-Asadi A, Ayala GB, Goldberg LH, Vujevich J, Jih MH. The 20-minute rapid MART-1 immunostaing for malignant melanoma frozen sections. Dermatol Surg. 2008;34:498-500.

109. Kelley LC, Starkus L.Immunohistochemical staining of lentigo maligna during Mohs micrographic surgery using MART-1. J Am Acad Dermatol. 2002 Jan;46(1):78-84.

110. Newman J, Beal M, Schram SE, Lee PK. Mohs micrographic surgery for lentigo maligna and lentigo maligna melanoma using Mel-5 immunostaining: an update from the University of Minnesota. Dermatol Surg. 2013;39:1794-9.

111. Glass LF, Raziano RM, Clark GS, Higgins HW, Ladd S, Lien MH, et al. Rapid frozen section immunostaining of melanocytes by microphthalmia-associated transcription factor. Am J Dermatopathol. 2010;32:319-25.

112. Paraskevas LR, Halpern AC, Marghoob AA. Utility of the Wood's light: five cases from a pigmented lesion clinic. Br J Dermatol. 2005;152:1039-44.
MAILING ADDRESS:

Luiz Guilherme Martins Castro

Rua Mato Grosso 306 cj 604

01239-040 - São Paulo - SP

Brazil

Email:lgmc@oncoderma.com.br

How to cite this article: Castro LGM, Messina MC, Loureiro W, Macarenco RS, Duprat Neto JP, Di Giacomo THB, Bittencourt FV, Bakos RM, Serpa SS, Stolf HO, Gontijo G. Guidelines of the Brazilian Dermatology Society for diagnosis, treatment and follow up of primary cutaneous melanoma. Part I. An Bras Dermatol. 2015;90(6):851-61. 